Please cite as:

Cheng, M., Jin, X., \& Wong, I. A. (2014). Ecotourism site in relation to tourist attitude and further behavioural changes. Current Issues in Tourism, 17(4), 303-311. doi: 10.1080/13683500.2013.8000301.

\title{
Ecotourism site in relation to tourist attitude and further behavioural changes
}

Mingming Cheng ${ }^{\mathrm{a}}$, Xin Jin $^{\mathrm{b}}$ and IpKin Anthony Wong ${ }^{\mathrm{c}}$

a UTS Business School, University of Technology, Sydney, Australia

b Griffith University, Australia;

c Institute for Tourism Studies, Macao, People's Republic of China

\section{Introduction}

Despite the emergence of ecotourism in both practice and academic literature in China during recent decades, relatively little is known about the role of ecotourism sites, especially in relation to tourist attitude and behavioral change. The Chinese domestic tourism market has been witnessing rapid growth for the past few years. The China National Tourism Administration (CNTA)(2011) predicted that by the year 2015, the domestic tourism population should reach 3.3 billion. Although there is no official figure regarding the number of domestic visitors traveling to ecotourism site, it has been noted that many of China's reservation areas receive millions of visitors each year (Buckley et al., 2008). Nevertheless, the growth of demand for ecotourism in China ran ahead of the supply of these products, resulting in new challenges for those stakeholders involved in managing the sites and a growing threat over ecologically sensitive areas(Nianyong \& Zhuge, 2001).

In the international tourist market, the undesirable behavior of Chinese tourists has been reported (South Weekend, 2006; Zeng, 2006; Zhang, 2006). Among the most frequent undesirable behaviors reported on line, "inscribing names on walls or pillars", "spitting", "talking loudly", and "randomly littering" are common forms seen in tourists spots favored by Chinese holidaymakers (Zeng, 2006; Zhang, 2006); however, these behaviors are generally not perceived to be improper in domestic destinations. Similarly, Chinese tourists are more interested in sightseeing rather than promoting environmental conservation while visiting ecotourism sites (Cheng and Wong, 2012). The undesirable behavior could pose a potential threat to stakeholders involved in the management of an ecotourism site as the number of tourist arrivals continue to increase. Therefore, understanding the motives of the tourists in relation to their attitude change, and further adaptation of desirable behaviors through their visit to ecotourism sites would assist resource 
managers, ecotourism operators, local residents and policy makers to develop a comprehensive ecotourism plan.

\section{2: Ecotourism sites}

Although there is a common consensus among academics and practitioners on what should be deemed to be an ecotourism site, virtually all the study sites chosen in the ecotourism literature are protected natural areas (Weaver \& Lawton, 2007).

From an ecological perspective, an ecological site, in general, is defined to be nature-based with an ecological value. In the case of Alberta Canada, an ecological site is defined as an area with a unique recurring combination of vegetation, soil, landform, and other environmental components (Albert Environment, 2002). The Society for Range Management (SRM) (1989) defined an ecological site as "a kind of land with a specific potential natural community and specific physical site characteristics, differing from other kinds of land in its ability to produce vegetation and to respond to management" (as cited by Thorpe, 2007,pp.5)

In the substantial body of ecotourism literature during the last two decades, ecotourism sites have generally been referred to as relatively undisturbed/undeveloped natural areas, e.g. natural reserves (Lindberg et al., 2003; Tao, Eagles, \& Smith, 2004), mountainous areas with unspoiled physical and cultural characteristics with limited access (Holden \& Sparrowhawk, 2002), new forms of ecotourism-related sites, e.g. organic farms (Choo \& Jamal, 2009), small natural islands (Maroudas \& Kyriakaki, 2001), desert areas (Reichel, Uriely, \& Shani, 2008) and national park with ecotourism accreditation status (Weaver \& Lawton, 2002). Some researchers even impose more strict principles for defining an ecotourism site, e.g a relatively undisturbed natural area that is more than $40 \mathrm{~km}$ from home (Blamey, 1995). However, this restricted approach may not necessarily transfer into the concept of ecotourism in China as researchers pointed out that in the context of China, to be with nature does not mean to experience hard-ship or to experience wilderness as proposed by western scholars (Xu, Ding, \& Packer, 2008). The same authors also noted that although Western culture has substantive influence on the new Chinese generation in their tendency to follow the fashion of searching for adventure and excitement, for most people the traditional Chinese culture imposes constraints on travelling far to visit remote and unknown areas.

In the context of China, researchers generally have acknowledged or chosen national parks e.g. wetland park (He \& Wang, 2003; Wang, Chen, Fan, \& Lu, 2012), national forest park (Deng, Qiang, Walker, \& Zhang, 2003), Yunnan Great Rivers National Parks (Cater, 2000), new form "ecotourism" sites - "Nong Jia Le" (NJL) (Newton \& Franklin, 2011) or nature reserves e.g. biosphere reserves with international accreditation status ( $\mathrm{Li}, 2004)$, as typical ecotourism sites for their study. 
Although researchers have pointed out that private protected areas appear to be emerging as an increasingly popular alternative venue compared with public protected areas but are poorly understood (Buckley, 2004; Weaver \& Lawton, 2007), this advocacy may not necessary to be fully integrated into the context of China as nearly all the sites are publicly owned and their operators will only have limited terms of service based on the land contract with government.

A number of researchers have noted that in the context of China, most of domestic ecotourism sites are not only based on nature but also on cultural landscapes, and have advocated that natural landscape and cultural landscape are hardly separable (Buckley, Cater, Linsheng, \& Chen, 2008; Wen \& Ximing, 2008). This could be explained by traditional Chinese philosophy "Feng Shui", as Feng Shui has endured as an art of site selection in China for more than 3,000 years and still remains popular(Han, 2001). Feng Shui, in simple terms, means integration of both nature and culture to pursue a balance and harmony between people and nature as well as among people. Also, the Chinese way of thinking, originated as early as 1930, has been recently argued by a considerable of scholars that influence the perception of Chinese tourists on ecotourism. Putting it into simple terms, the Chinese way of thinking is a relational thinking, i.e. "they tend to think about and learn things in the way that things could be associated with them" (Xu, Cui, Ballantyne, \& Packer, 2013, pp. 119). Therefore, Chinese tourists would tend to find a relationship between nature and human being, whereas their western counterpart's view tends to find reality in mechanics(Buckley et al., 2008; Xu et al., 2013). As ancient philosophies that originated in China, Feng Shui and the Chinese way of thinking is profoundly intertwined with many aspects of Chinese life and this could inevitably influence how Chinese tourists perceive an ecotourism site. Ma (2002) has identified categories of ecotourism sites and related eco-tourism products in China, but unfortunately, the author did not seem to give the criteria on which definition of ecotourism site should be based. Also, Weaver \& Lawton (2007) noted that few of those empirical supply-side studies have properly addressed protected areas as an ecotourism topic in its own right. It seems that ecotourism site, as an important component of an overall eco-tourism experience, has not been properly addressed. Therefore, in the current research context where there is relatively little definition of ecotourism site, especially in the context of China, ecotourism sites, are physical places (or groups of places) in which include a relatively undisturbed natural area with native flora, fauna and other natural resources and their associated cultural components as attractions to offer an ecotourism experience.

\section{Visitor Management}

In the arena of research into visitor management, researchers advocate that visitor management has become one of the important means of government and 
public agencies alike of managing the impacts of tourism (Mason, 2005). In the past 20 year or so, scholars also point out that studying tourists' on-site behaviors in the field of visitor management could serve as a significant way to help reduce the negative impacts of tourism (Grossberg, Treves, \& Naughton-Treves, 2003; Orams \& Hill, 1998; Mason, 2005). In particular, modification of visitor's behavior has been consistently regarded as a key principal to maintain a sustainable destination development, which could be done through education, enlightenment and establishment of code of conduct (Robinson, Heitmann, \& Dieke, 2011). In line with this, the importance of sustainable on-site behaviors has been highlighted as an important tool to maintain an authentic on-site experience for tourists (Pearce, 2005). When it comes to ecotourism setting, the educational role of ecotourism has been consistently acknowledged by scholars in that ecotourism experiences can enhance environmental knowledge, which serves as a key component in the transformation of environmental attitudes and the development of an environmental consciousness that could result in changing environmental behaviors(Higgins-Desbiolles, 2009; Walter, 2012; Weaver \& Lawton, 2007). To the best knowledge of the researcher, Higgins-Desbiolles (2009) has conducted an empirical study on the role of ecotourism in relation to tourist attitude change and the results reveal the indigenous ecotourism's role in transforming tourists' ecological consciousness. Therefore, these existing literatures provide a foundation of researcher's assumption that there might be similar attitude changes and further adaptation of sustainable tourist behavior from Chinese domestic tourists after their visit to ecotourism sites. In this regard, an empirical research taking into the cultural and geographical context in examining Chinese tourist attitude changes in relation to their visit to ecotourism sites is essential as noted by previous researchers (Xu et al., 2013) that this could help ecotourism sites to have a successful development of culturally appropriate and effective strategies in China that engage tourists, enhance their appreciation, and encourage further sustainable behavioral changes.

\section{Methodology}

\subsection{The qualitative approach}

This study aims to explore the role of ecotourism site in relation to Chinese tourist attitude and further behavioral change. Given that there is relatively little knowledge in the current literature in understanding the role of ecotourism site in China, the researcher employs a qualitative research approach through in-depth interviews and on-site observation with Chinese domestic tourists. In-depth interview is considered most appropriate in the current research context as it allows the researcher to gain an in-depth understanding of the role of ecotourism site within the country. On-site observation would enhance the reliability of the interview results as the use of multiple data collection methods tests one source of information against another and dissects alternative explanations by introducing different evidence from different perspectives (Mehmetoglu \& Altinay, 2006). 


\subsection{Study Methods}

In order to diversify the investigation setting to yield a better result, the ecotourism sites selected are national forestry parks (i.e.Tianmu Mountain), world natural heritage site (i.e.Yellow Mountain), and national wetlands (i.e.Xixi National Wetland).The three ecotourism sites chosen have not only been based on the aforementioned definition but also widely acknowledged by the Chinese National Geographic as typical ecotourism sites in China. Although these three sites chosen may not necessarily be regarded by Chinese domestic tourist as ecotourism sites, this could yield higher possibility that the sites chosen offer an ecotourism experience. Tianmu Mountain is a UNESCO Biosphere Reserve and appeals primarily for its natural plants with more than 2,000 species. Yellow Mountain is a UNESCO World Heritage Site and it is best known for its "four wonders" including peaks, spectacular rocks, odd-shaped pines, and a sea of clouds. Also, the name of Yellow Mountain is well embedded in Chinese literature and paintings. Xixi National Wetland has not only rich ecological resources but also a profound culture, with more than 1,800 years history. The park consists of six main watercourses including scatter various ponds, lakes and swamps. Because of the physical environment on accessibility, Yellow Mountain, and Tianmu Mountain requires more involvement from the tourists than that of Xixi Wetland, as Xixi Wetland is located less than $5 \mathrm{~km}$ from West Lake and is often regarded as a rare urban wetland. The main activity for Yellow Mountain is trekking, whereas Tianmu Mountain has both trekking and "Nong Jia Le" (Happy Farmer's House) - a stay in farmhouses, with fresh air, green trees and organic food. For Xixi National Wetland, it includes a 20 minute boat shuttle to get into the park, a visit to former residences and museums of fisherman and farmers, and meals on a boat while watching the natural view.

The researcher in this study is a native mainland Chinese. Informants were recruited from a purposive sample selected because the researcher was able to gain access to the three selected ecotourism sites in China through his relationship with the site managers. Thus, the researcher was able to select a roughly equal number of males and females with two age categories - 12 young tourists and 16 old tourists. Overall, there were 15 male informants and 13 female informants. Their age ranged from 22 to 57 years old. Most of the informants are first time visitors to the ecotourism sites. The informants selected are from first-tier cities, namely Beijing, Shanghai and Guangzhou as tourists from those regions are the primary consumers in visiting ecotourism sites in China.

The final interview and field guideline in this study was based on both intensive literature review and discussion with tourism academics. The researcher first conducted three in-depth interviews to enhance his theoretical sensitivity and to test the interview and field guide as this could increase the dependability of the study. 
After several iterations, the interview and field guide was finalized in order to reflect the purpose of this study.

In order to mitigate the memory effect, the researcher interviewed the informants in the hotels where they stayed as permitted right after their visit to the selected ecotourism sites in July and August 2012. All interviews were conducted face-to-face in the lobby of the aforementioned hotels. Informants were asked first whether any changes occurred after the visit and then followed with what changes they have experienced after visiting ecotourism sites and the reasons behind. In order to make the informants more comfortable and to maximize mutual understanding, the interviews were conducted and written in Chinese. Additional information about the way and the context in which the interview was conducted was also written down during and after each interview. The interviewer also ensured anonymity of the informants and allowed free exchange of information. In addition, the interviewers strived to avoid misinformation or evasions of the issues being discussed by the informants. Each interview lasted 20 to 35 minutes. The interview guides and transcripts were prepared both in Chinese and English.

Regarding on-site observation, through his relationship with site managers, the researcher acted as a tourist and followed other tourists as a group to travel around the ecotourism sites. The researcher spent around two days at each selected ecotourism site. In particular, the researcher stayed around two hours per pre-selected sites in the spots identified by the site management office, where the most frequent undesirable and desirable behavior occurred. The researcher took note of the way and the context in which the tourists talked and behaved during their visit.

The researcher continued conducting the interviews for one month until theoretical saturation was reached. A total of 28 interviews were completed, which corresponds to over 90 pages of transcript. Because the first three interviews were used for the pilot test, only 25 interviews were used for further qualitative data analysis. The researcher followed the open coding method and read and reread the transcript line-by-line until categories of meaning emerged, and constant comparison was utilized to code the incidents and categories within and across the informants(Glasser \& Strauss, 1967). The extant literature and on-site observation notes were also introduced during the coding process. Then the interpretations of the findings were then expanded and refined. After several iterations, the outcomes were finalized as this process helps to reduce the researchers' bias and to ensure that the interpretations are the results of Chinese domestic tourists and the investigated phenomena. 


\section{Results}

Our findings show a great difference between the younger and older informants with regard to their perceptions of their attitude and behavioral changes. The older informants in this study generally agreed that they have become more environmentally conscious and try to follow a new environmental friendly life style whereas the younger counterparts are equivocal about the changes. Some younger informants claimed that they didn't change as they had already been following an environmentally friendly lifestyle before visiting ecotourism sites However, they generally agreed that they might have experienced attitude and behavioral changes without realizing it.

When I came back, I feel healthier as I did exercises. Then, I started to pay more attention to my lifestyle now. I am more environmentally friendly and I want to do more hiking and trekking so that it will help with my health. I even will walk to work for conservation of energy as well as my health. (Michelle, 45, Female)

I am not sure whether my behavior has been changed as I am always environmentally friendly. In my life, I stick to a low-carbon life. Well, it may have changed but I might not be aware of it. Even though I may have changed, it wouldn't be that much. (Kristy, 23, Male)

Two major themes have emerged throughout the interview in relation to informants' attitude change and further adaptation of desirable behavior via their ecotourism experience, including the unity with nature and human beings, and the perceived physical and psychological health benefits Each reason, as suggested by the informants, significantly influences their attitude changes, and might further facilitate their environmental behavioral changes.

The traditional view of the unity with nature and human being has been a major part in the ancient Chinese history and still remains popular. Chinese were educated to respect nature in order to create harmony with human beings. This is reflected in our findings as informants often suggested that human beings rely on nature, and nature becomes a comfortable habitat for human beings. Also, the informants unanimously perceived that the physical and psychological health benefits associated with their visit to ecotourism site greatly influenced their attitude and behavioral change.

I look for the harmonious relationship between nature and human beings. Only nature can offer our human beings a better life. When you emerse yourself in the natural environment, you feel you are part of it. Therefore, I feel that I will value the environment. Then it makes me feel more environmental conscious. 
Also, when I am at the ecotourism site, I feel healthier both physically and psychologically. I could get closer to nature to breathe the fresh air as I live in a city that is quite polluted. The city is full of noises and it is very crowded and commercialized. I feel nature is so important.(Bruce, 22, Male)

The environment in ecotourism sites is better than that of my original place and I feel very comfortable. You can't separate the environment with travel and I will feel very bad if we damage the environment. Also, fresh air and the nature (at the ecotourism site) could help purify my mentality. Therefore, I realize the importance of (the ecotourism sites) to my health, as it helps me to relax and forget the pressure from work and life (Jenson, 45, Male)

Interestingly, the perceived health benefits have been extended to ecotourism food (green food) as the majority of the informants kept mentioning ecotourism food across the interview (or green food), as it was one of the main activities that they would engage and value during their trip. Ecotourism food helps tourists realize the importance of healthy food and thus, lead to their appreciation of nature. The findings probably reflect the food safety concerning the well-developed three biggest cities in China; thus, ecotourism food serves as a tangible cue that provides tourists with appreciation of the natural environment

The second reason will be that I could have green food in the ecotourism sites as the environmental awareness has been raised [here at the site]. In contrast, there is a lot of non-organic food in the city. We are aware that the food in the city is not that healthy; hence we are looking for green food here at the site. (Tom, 45, Male)

My priority going to the site is to be healthier. As the food provided at the site is home-made without pollution. I live in the city so I couldn't get those food. In fact, I feel that the food is not that safe in the city. On the other hand, I feel safe eating the food here, and I also feel that it tastes better than those in the city. (Lilian, 23, Female)

\subsection{Discussion and Conclusion}

With the rapidly growing wealth of Chinese citizens and increasing health consciousness of Chinese tourists, it is predicted that there will be a dramatic increase in Chinese tourists visiting ecotourism sites domestically and internationally. Understanding the role of ecotourism sites in Chinese domestic tourist attitude and perhaps further behavioral changes would help ecotourism site managers, ecotourism operators, and policy makers to maintain an effective management of the ecotourism sites. Findings of this study could be further used in other spots to increase the environmental awareness of Chinese tourists and to 
mitigate undesirable behavior.

Findings of this study show that health benefits perceived by Chinese tourists play important roles in their attitude change and perhaps further adaptation of environmental behavior, as informants perceived that being with nature could place them mentally and physically into a comfortable environment so that they could relax and do physical exercises. The informants also suggested that the ultimate goal of being healthy is to achieve both mentally and physically, and this could only be achieved in a natural environment. This could possibly be explained by the deep rooted ecological value of unity of nature and human beings as the informants pointed out that human beings rely on nature, and nature becomes a comfortable habitat for humans. However, as noted by previous researchers (Wen \& Ximing, 2008), this ecological value originated in ancient China was seldom investigated in the social practices. Nevertheless, this finding is consistent with the previous researchers in that physical health is regarded as a primary benefit of travel for Asians (Buckley, 2004; Cheng \& Wong, 2012; Kerstetter, Hou, \& Lin, 2004). In addition, the perceived health benefits have also been extended to ecotourism food (green food). Food safety was expressed consistently by a considerable number of informants, and it could be one potential factor that encourages Chinese tourists to go to ecotourism site. This finding could be possibly explained by the fact that the confidence of Chinese on food quality and safety is low. As such, the perceived health benefits and ecotourism food serve as a tangible cue that provides tourists with appreciation of the natural environment; thus, it facilitates their attitude and further behavioral changes. Although whether the health benefits perceived by informants is long-lasting or not, it explicitly presents an important perceived value for Chinese domestic tourists. Nevertheless, this finding contributes to existing literature in understanding the importance of perceived health benefits of Asian tourists, especially Chinese tourists, travelling to ecotourism site. Market managers could utilize the findings of this study to collaborate with ecotourism sites to emphases the perceived health benefit and the ecological value of unity of nature and human beings in relation to the environment to effectively manage the ecotourism site carrying capacity.

This paper works to uncover a multitude of reasons understanding the role of ecotourism site, from perceived health benefits to the unity of nature and human beings. Based on a qualitative approach, our findings highlight an emerging yet under-studied research area in the body of ecotourism literature. This study also provides insight into how tourism authorities and ecotourism site managers could utilize perceived health benefits to educate Chinese tourists. Future research is encouraged to verify the findings of this study through quantitative methods and to conduct cross-cultural comparison with tourists originated from more individualistic countries in that Chinese society is collective in nature. 


\section{References}

Alberta Environment. (2002). Glossary of Reclamation and Remediation Terms used in Alberta. $7^{\text {th }}$ Edition. Retrieved from http://environment.gov.ab.ca/info/library/6843.pdf

Blamey, R. K. (1995). Ecotourism: the search for an operational definition. Journal of Sustainable Tourism, 5(2), 109-131.

Buckley, R. (2004). Ecotourism Land Tenure and Enterprise Ownership: Australian Case Study. Journal of Ecotourism, 3(3), 208-213.

Buckley, R., Cater, C., Linsheng, Z., \& Chen, T. (2008). SHENGTAI LUYOU: Cross-Cultural Comparison in Ecotourism. Annals of Tourism Research, 35(4), 945-968.

Cater, E. A. (2000). Tourism in the Yunnan Great Rivers National Parks System Project: prospects for sustainability. Tourism geographies, 2(4).

Cheng, M., \& Wong, A. (2012). A different look at Chinese Ecotourists Paper presented at the 18th Asia Pacific Tourism Association Annual Conference, Taipei, Taiwan.

Choo, H., \& Jamal, T. (2009). Tourism on organic farms in South Korea: a new form of ecotourism. Journal of Sustainable Tourism, 17(4), 431-454.

Deng, J., Qiang, S., Walker, G. J., \& Zhang, Y. (2003). Assessment on and Perception of Visitors' Environmental Impacts of Nature Tourism: A Case Study of Zhangjiajie National Forest Park, China. Journal of Sustainable Tourism, 11(6), 529-548.

Glasser, B. G., \& Strauss, A. L. (1967). The Discovery of Grounded Theory: Strategies for Qualitative Research. Hawthorne, NY: Aldine de Gruyter.

Grossberg, R., Treves, A., \& Naughton-Treves, L. (2003). The incidental ecotourist: Measuring visitor impacts on endangered howler monkeys at a Belizean archaeological site. Environmental Conservation, 30(1), 40-51.

Han, K.-T. (2001). Traditional Chinese Site Selection-Feng Shui: An Evolutionary/Ecological Perspective. Journal of Cultural Geography, 19(1), 75-96. 
He, P., \& Wang, B.-z. (2003). Landscape ecological assessment and eco-tourism development in the South Dongting Lake Wetland, China. Journal of Environmental Sciences (IOS Press), 15(2).

Higgins-Desbiolles, F. (2009). Indigenous ecotourism's role in transforming ecological consciousness. Journal of Ecotourism, 8(2), 144-160.

Holden, A., \& Sparrowhawk, J. (2002). Understanding the Motivations of Ecotourists: the Case of Trekkers in Annapurna, Nepal. International Journal of Tourism Research, 4, 435-446.

Kerstetter, D. L., Hou, J.-S., \& Lin, C.-H. (2004). Profiling Taiwanese ecotourists using a behavioral approach. Tourism Management, 25(4), 491-498.

Lindberg, K., Tisdell, C., Xue, D., Lew, A. A., Yu, L., Ap, J., \& Zhang, G. (2003). Chapter 7: Ecotourism in China's Nature Reserves. Tourism in China (pp. 103-125): Haworth Press, Inc

Maroudas, L., \& Kyriakaki, A. (2001). The Perspectives of Ecotourism Development in Small Islands of the South Dodecanese. Anatolia, 12(1), 59-71.

Mason, P. (2005). Visitor Management in Protected Areas: From 'Hard' to 'Soft' Approaches? Current Issues in Tourism, 8(2-3), 181-194.

Mehmetoglu, M., \& Altinay, L. (2006). Examination of grounded theory analysis with an application to hospitality research. International Journal of Hospitality Management, 25(1), 12-33.

Newton, J., \& Franklin, A. (2011). Delivering sustainable communities in China: using a sustainable livelihoods framework for reviewing the promotion of “ecotourism” in Anji. Local Environment, 16(8), 789-806. doi:

Nianyong, H., \& Zhuge, R. (2001). Ecotourism in China's Nature Reserves: Opportunities and Challenges. Journal of Sustainable Tourism, 9(3), 228-242. doi: 10.1080/09669580108667400

Orams, M. B., \& Hill, G. J. E. (1998). Controlling the ecotourist in a wild dolphin feeding program: Is education the answer? Journal of Environmental Education, 29(3), 33-38.

Pearce, P. L. (2005). Tourist Behaviour : Themes and Conceptual Schemes: Channel View Publications. 
Reichel, A., Uriely, N., \& Shani, A. (2008). Ecotourism and Simulated Attractions: Tourists' Attitudes Towards Integrated Sites in a Desert Area. Journal of Sustainable Tourism, 16(1), 23-41. doi: 10.2167/jost711.0

Robinson, P., Heitmann, S., \& Dieke, P. U. C. (2011). Research Themes for Tourism. Wallingford, Oxon, GBR: CABI Publishing.

Tao, C.-H., Eagles, P. F. J., \& Smith, S. L. J. (2004). Implications of Alternative Definition of Ecotourists. Tourism Analysis, 9, 1-13.

Thorpe, J. (2007). Ecoregions and Ecosites. Alberta: Saskatchewan Research Council

Walter, P. G. (2012). Theorising visitor learning in ecotourism. Journal of Ecotourism, $1-18$.

Wang, W., Chen, J. S., Fan, L., \& Lu, J. (2012). Tourist experience and Wetland parks: A case of Zhejiang, China. Annals of Tourism Research, 39(4), 1763-1778.

Weaver, D. B., \& Lawton, L. J. (2002). Overnight Ecotourist Market Segmentation in the Gold Coast Hinterland of Australia. Journal of Travel Research, 40(3), 270-280. doi: 10.1177/004728750204000305

Weaver, D. B., \& Lawton, L. J. (2007). Twenty years on: The state of contemporary ecotourism research. Tourism Management, 28(5), 1168-1179.

Wen, Y., \& Ximing, X. (2008). The Differences in Ecotourism between China and the West. Current Issues in Tourism, 11(6), 567-586.

Xu, H., Cui, Q., Ballantyne, R., \& Packer, J. (2013). Effective environmental interpretation at Chinese natural attractions: the need for an aesthetic approach. Journal of Sustainable Tourism, 21(1), 117-133.

Xu, H., Ding, P., \& Packer, J. (2008). Tourism Research in China: Understanding the Unique Cultural Contexts and Complexities. Current Issues in Tourism, 11(6), 473-491.

South Weekend. (Sept 28, 2006). The Chinese tourists' improper behaviors shook the high level officers. Retrieved from http://news.sina.com.cn/c/2006-09-28/093911126173.shtml

Zeng, C. (2006, October 5). Chinese travelers' uncivil liberties. Retrieved from http://www.atimes.com/atimes/China/HJ05Ad01.html 
Zhang, R. (2006, October 8). Chinese tourists' bad behavior to be curbed. Retrieved from http://www.china.org.cn/english/2006/Oct/183079.htm 